\title{
Bioavailability of Iron from Purple Laver (Porphyra spp.) Estimated in a Rat Hemoglobin Regeneration Bioassay
}

\author{
Ning-Sing Shaw* and Yu-Hui Liu ${ }^{\dagger}$ \\ Department of Agricultural Chemistry, National Taiwan University, Taipei, \\ Taiwan 10764, Republic of China
}

\begin{abstract}
Laver belongs to the genius of Porphyra and is the most valuable seaweed in the aqua-culture industry. It contains higher iron than many other plant foods. The bi oavailability of iron from laver was evaluated in a rat hemogl obin regeneration assay. Reagent-grade ferrous sulfate was used as the reference standard, and the relative biological value (RBV) for laver was expressed as a percentage of the response to ferrous sulfate. RBV was calculated by two methods: slope-ratio and ratio of hemoglobin regeneration efficiency, and both yiel ded RBV of 26 for laver. Amount of available iron from laver estimated from RBV was comparable to many iron-fortified foods.
\end{abstract}

Keywords: Iron bioavailability; laver; Porphyra spp.; relative biological value; hemoglobin regeneration bioassay

\section{INTRODUCTION}

Laver is a type of red algae belonging to the genus Porphyra. Modern aqua-cultivation of Porphyra occurred in the 1960s as a result of the discovery of the Conchocel is phase of Porphyra, which allowed artificial seeding and maximizing production under controlled conditions. Laver has been a staple in the diet of Asian cultures, such as China and J apan, and dried laver appears to be the most widely eaten seaweed in the world. It contains various biologically active substances beneficial to human health, induding significant amounts of nutrients such as protein and free amino acids, vitamins $C, B$ groups, and $A$, and trace minerals such as zinc, copper, manganese, and selenium (Noda, 1993). Dried laver contains vitamin $B_{12}$ in comparable amounts to animal foods (Watanabe et al., 1999; Yamada et al., 1996) and is an excellent source for strict vegetarians. In addition, components such as porphyran, a sulfated polysaccharide, porphyosin and pigments were reported to exhibit medical benefits including antitumor (Noda et al., 1990), antiulcer (Noda, 1983), and antimutagenic activities (Okai et al., 1996).

Dried laver also has higher iron concentration (> 28 mg per $100 \mathrm{~g}$ dry matter) than most plant foods (FAO, 1972). Since iron deficiency still occurs in both developing and developed countries (U nited Nations ACC/SCN, 1992), natural foods rich in iron provide an alternative choice other than iron fortification for improving iron nutrition. However, plant foods usually have components that inhibit iron absorption (Hallberg, 1981), and availability of iron from laver was evaluated in a rat hemoglobin regeneration bioassay (AOAC, 1995; Fritz et al., 1974; Rotruck and Luhrsen, 1979) before its novel use as an iron source.

* To whom correspondence should be addressed. Tel: 886-2-23621301. Fax: 886-2-23621301. E-mail: nsshaw@ ccms.ntu.edu.tw.

${ }^{\dagger} \mathrm{F}$ ood I ndustry Research and Development I nstitute, Hsinchu 300 Taiwan.

\section{MATERIALS AND METHODS}

Diets. Dry purple laver (Porphyra spp.), purchased from a local supermarket, was oven dried at $65^{\circ} \mathrm{C}$ for $6 \mathrm{~h}$, ground to pass a 20-mesh screen, and stored in plastic bags at room temperature. Proximate analysis of dried laver resulted in compositions as follows: moisture $6.0 \%$, crude protein $28.8 \%$, crude fat $0.5 \%$, crude fiber $2.8 \%$, crude ash $15.5 \%$, and nitrogen-free extract $46.5 \%$. Measured iron concentration was $0.91 \mathrm{mg}$ per gram dried laver.

The depletion diet was formulated according to AI N-76 with some modifications (American Institute of Nutrition, 1977). Ingredients $(\mathrm{g} / \mathrm{kg})$ were as follows: corn starch (CERESTAR, France), 621; casein (ICN, Ohio), 200; soybean oil, 100; cellulose (Vitacel M80 from IRS, Germany), 30; mineral mixture (AIN-76 with ferric salt omitted), 35; vitamin mixture (AIN-76), 10; choline chloride, 3; and L-methionine, 1. This depletion diet contained less than $3 \mathrm{mg}$ of $\mathrm{Fe}$ per $\mathrm{kg}$. F or the standard regeneration diets, ferrous sulfate $\left(\mathrm{FeSO}_{4} \cdot 7 \mathrm{H}_{2} \mathrm{O}\right)$ was added to the depletion diet to supply $6,12,18$, and $35 \mathrm{~g}$ of added iron per kilogram of diet. F or laver regeneration diets, dried laver from 7.4 to $74 \mathrm{~g}$ was added to one kilogram of the depletion diet to provide $6,12,18,24,40$, and $60 \mathrm{~g}$ of added iron per kilogram of diet and replaced equivalent amounts of corn starch and casein. Iron concentration in the diets was verified by analysis. Ingredients used in the mineral and vitamin mixtures were obtained from Sigma.

Animals and Bioassay. Weanling male Wistar rats (Laboratory Animal Center, College of Medicine, National Taiwan University) weighing $55 \pm 7 \mathrm{~g}$ were housed individually in stainless steel cages with wire mesh floors in an animal room where temperature was controlled at a constant $25^{\circ} \mathrm{C}$ with 12-h light/dark periods. F ood and deionized water were freely available. Animal care and handling conformed to the NSC's Guidelines for Use and Care of Laboratory Animals (National Science Council, 1993). Body weight and feed intake corrected for spillage were recorded twice a week. In the depletion period, rats had free access to the depletion diet, and blood for monitoring hemoglobin concentration was drawn from the tail. The average hemoglobin concentration was sufficiently low $(0.72 \pm 0.11 \mathrm{mmol} / \mathrm{L})$ by the 16th day, and average body weight was $125 \pm 13 \mathrm{~g}$.

In the beginning of the regeneration period, seven rats were all otted to each of 11 groups in such a manner that all groups had similar mean values of hemoglobin concentration and body 
Table 1. Changes of Body Weight and Feed Efficiency in Rats during the 14-Day Regeneration Period of the Rat Bioassay

\begin{tabular}{|c|c|c|c|c|c|}
\hline diets & $\begin{array}{l}\text { iron added } \\
(\mathrm{mg} / \mathrm{kg})\end{array}$ & $\begin{array}{l}\text { final body wt } \\
\text { (g/rat) }\end{array}$ & $\begin{array}{l}\text { body wt gain } \\
\text { (g/rat) }\end{array}$ & $\begin{array}{l}\text { food intake } \\
\text { (g/rat) }\end{array}$ & $\begin{array}{l}\text { feed efficiency } \\
\text { (g gain/g food) }\end{array}$ \\
\hline depletiona & 0 & $158 \pm 21^{b}$ & $36 \pm 11^{b}$ & $139 \pm 17^{b}$ & $0.26 \pm 0.06^{b}$ \\
\hline \multirow{4}{*}{ standard $\mathrm{FeSO}_{4}$} & 6 & $199 \pm 25$ & $73 \pm 11$ & $187 \pm 23$ & $0.39 \pm 0.04$ \\
\hline & 12 & $200 \pm 18$ & $82 \pm 7$ & $192 \pm 17$ & $0.43 \pm 0.03$ \\
\hline & 18 & $209 \pm 10$ & $90 \pm 8$ & $215 \pm 14$ & $0.42 \pm 0.06$ \\
\hline & 35 & $217 \pm 9$ & $87 \pm 13$ & $220 \pm 11$ & $0.39 \pm 0.05$ \\
\hline \multirow[t]{6}{*}{ laver } & 6 & $182 \pm 11$ & $51 \pm 9 c$ & $161 \pm 10^{c}$ & $0.32 \pm 0.05^{c}$ \\
\hline & 12 & $193 \pm 21$ & $69 \pm 15$ & $184 \pm 23$ & $0.37 \pm 0.05$ \\
\hline & 18 & $190 \pm 29$ & $65 \pm 18$ & $176 \pm 33$ & $0.37 \pm 0.04$ \\
\hline & 24 & $205 \pm 18$ & $77 \pm 8$ & $188 \pm 14$ & $0.41 \pm 0.02$ \\
\hline & 40 & $208 \pm 15$ & $83 \pm 11$ & $201 \pm 19$ & $0.41 \pm 0.03$ \\
\hline & 60 & $212 \pm 11$ & $85 \pm 10$ & $206 \pm 14$ & $0.41 \pm 0.05$ \\
\hline
\end{tabular}

a I ron concentration was $<3 \mathrm{mg} / \mathrm{kg}$. Values in this group are significantly lower than those of all other dietary groups by Duncan's multiple range test at $p<0.05$. ${ }^{b}$ Each value was mean \pm SD of seven rats. ${ }^{c}$ Significantly lower than the standard groups and other laver groups by Duncan's multiple range test at $p<0.05$.

Table 2. Hemoglobin and Iron Responses in the Rat Hemoglobin Regeneration Assay of Laver Iron

\begin{tabular}{|c|c|c|c|c|c|c|}
\hline diets & $\begin{array}{l}\text { iron added } \\
(\mathrm{mg} / \mathrm{kg})\end{array}$ & $\begin{array}{l}\text { intake of added iron } \\
\text { ( } \mu \mathrm{mol} / \mathrm{rat})\end{array}$ & $\begin{array}{l}\text { hemogl obin regenerated } \\
(\mathrm{mmol} / \mathrm{L})\end{array}$ & $\begin{array}{l}\text { hemogl obin gain } \\
\text { (nmol/rat) }\end{array}$ & $\begin{array}{l}\text { hemogl obin Fe gain } \\
\qquad(\mu \mathrm{mol} / \mathrm{rat})\end{array}$ & $\begin{array}{l}\mathrm{HRE}^{\mathrm{a}} \\
(\%)\end{array}$ \\
\hline depletion & 0 & $0 \pm 2^{b}$ & $0.57 \pm 0.15^{b}$ & $0.4 \pm 1.0^{b}$ & $1 \pm 4^{b}$ & \\
\hline \multirow{4}{*}{ standard $\mathrm{FeSO}_{4}$} & 6 & $20 \pm 2$ & $0.86 \pm 0.11$ & $5.4 \pm 1.2$ & $22 \pm 5$ & $110 \pm 8$ \\
\hline & 12 & $41 \pm 4$ & $1.16 \pm 0.12$ & $9.8 \pm 1.9$ & $40 \pm 7$ & $97 \pm 5$ \\
\hline & 18 & $69 \pm 4$ & $1.57 \pm 0.13$ & $16.3 \pm 1.8$ & $66 \pm 7$ & $96 \pm 3$ \\
\hline & 35 & $138 \pm 7$ & $1.96 \pm 0.07$ & $22.5 \pm 2.5$ & $92 \pm 10$ & $67 \pm 3^{c}$ \\
\hline \multirow[t]{6}{*}{ laver } & 6 & $17 \pm 1$ & $0.64 \pm 0.09$ & $1.4 \pm 1.0$ & $6 \pm 4$ & $33 \pm 9^{d}$ \\
\hline & 12 & $39 \pm 5$ & $0.67 \pm 0.03$ & $2.4 \pm 0.8$ & $10 \pm 3$ & $25 \pm 2^{d}$ \\
\hline & 18 & $56 \pm 11$ & $0.76 \pm 0.09$ & $3.7 \pm 1.1$ & $15 \pm 5$ & $28 \pm 4^{d}$ \\
\hline & 24 & $81 \pm 6$ & $0.78 \pm 0.07$ & $4.5 \pm 0.7$ & $18 \pm 3$ & $23 \pm 1^{d}$ \\
\hline & 40 & $144 \pm 14$ & $1.05 \pm 0.05$ & $8.6 \pm 1.2$ & $35 \pm 5$ & $25 \pm 1^{d}$ \\
\hline & 60 & $221 \pm 15$ & $1.33 \pm 0.08$ & $12.9 \pm 1.4$ & $52 \pm 6$ & $24 \pm 1^{d}$ \\
\hline
\end{tabular}

a Ratio of hemogl obin Fe gain to intake of added Fe. ${ }^{b}$ Each value was mean \pm SD of seven rats. c Significantly lower than other three standard diets. ${ }^{d}$ Significantly lower than all the standard diets, but no difference among the laver diets.

weight. One group of rats continued on the depletion diet. F our groups were fed the standard regeneration diets, and six groups were fed the laver regeneration diets. The regeneration period lasted for 14 days, and at the end rats were killed by carbon dioxide asphyxiation after body weight was recorded. Blood was collected from the abdominal vena cava into heparin-containing tubes for immediate analysis.

Analysis. Samples of dried laver, the depletion diet, the standard diets, and the laver regeneration diets were first digested by nitric acid in a microwave digestion oven (MLS1200 MEGA, Milestone). I ron concentration was measured with an atomic absorption spectrophotometer (Model 3100, Perkin-Elmer Co.) with air-acetylene flame at $248.3 \mathrm{~nm}$. Hemoglobin was determined colorimetrically by the cyanomethemoglobin method using Drabkin's reagent (Crosby and Munn, 1954).

Calculation. I ntake of the added iron was calculated from food intake and the concentration of added iron in the diets. Total circulating hemoglobin and hemoglobin iron were calculated on the assumption that $6.7 \%$ of body weight is blood volume (Mahoney and Hendrick, 1982) and that hemoglobin contains $0.34 \%$ iron (Miller, 1982). The hemogl obin iron gain was calculated as the difference between total hemogl obin iron at the end and beginning of the regeneration period. The hemogl obin regeneration efficiency (HRE) was calculated as the percentage of added iron consumed that was retained in circulating hemogl obin (Mahoney and Hendrick, 1982, F orbes et al., 1989). The relative biological value (RBV) of iron in laver compared to that of ferrous sulfate was calculated by two methods: the slope-ratio procedure (Miller, 1977) and the ratio of HREs (Mahoney and Hendrick, 1982).

Statistical Analysis. Differences among all the dietary groups were tested by Duncan's multiple range test. Except for the standard regeneration group of $35 \mathrm{mg}$ of Fe per kg diet, data from individual rats were used in the regression analysis of hemogl obin response on iron intake or dietary iron concentrations for each iron source in the regeneration period.
Standard procedures for regression analysis were used with no assumption about the point of intersections. All statistics were carried out using the SAS System (version 6, SAS Institute, Cary, NC).

\section{RESULTS}

Growth and Food Consumption. Body weight gain and food intake increased as the levels of iron supply increased either as ferrous sulfate or as laver (Table 1). Rats fed on the depletion diet throughout had the lowest body weight, weight gain, and feed efficiency. Except for the group fed the laver diet at $6 \mathrm{mg} \mathrm{Fe} / \mathrm{kg}$ diet, rats fed on laver diets had weight gain, food intake, and feed efficiency comparable to rats fed standard diets.

Hemoglobin and I ron Response. The regenerated hemoglobin concentrations and gains in total hemoglobin and in hemoglobin iron all increased as the iron supply increased in both standard and laver groups (Table 2). Rats fed on the depletion diet throughout had the lowest response for all these measures.

The HRE reached almost $100 \%$ in the standard groups at 6, 12, and $18 \mathrm{mg} \mathrm{Fe} / \mathrm{kg}$ diet and averaged $101 \%$, but it was significantly lower in the standard group of $35 \mathrm{mg} \mathrm{Fe} / \mathrm{kg}$ diet (Table 2). All the laver groups had significantly lower HRE than the standard groups, and the average was $26.3 \%$. The relative biological value of laver iron based on HRE was $26 \%$

Regression Analysis. All of the dose-response lines in this experiment were essentially linear ( $r^{2}$ ranged from 0.84 to $0.94, p<0.0001$; Figure 1 ), and intersections from the two dietary groups converged. The regression pattern met the requirements for the sloperatio model, and relative biological values for laver iron 


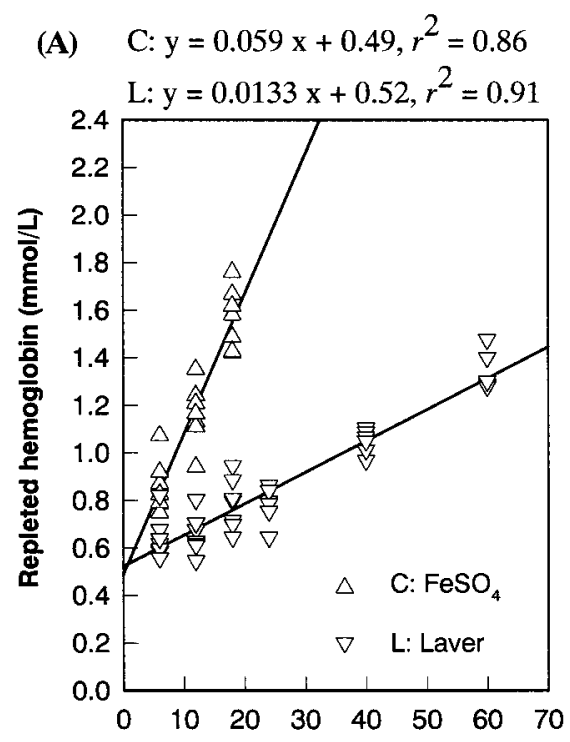

(C) $\mathrm{C}: \mathrm{y}=0.0145 \mathrm{x}+0.57, r^{2}=0.90$
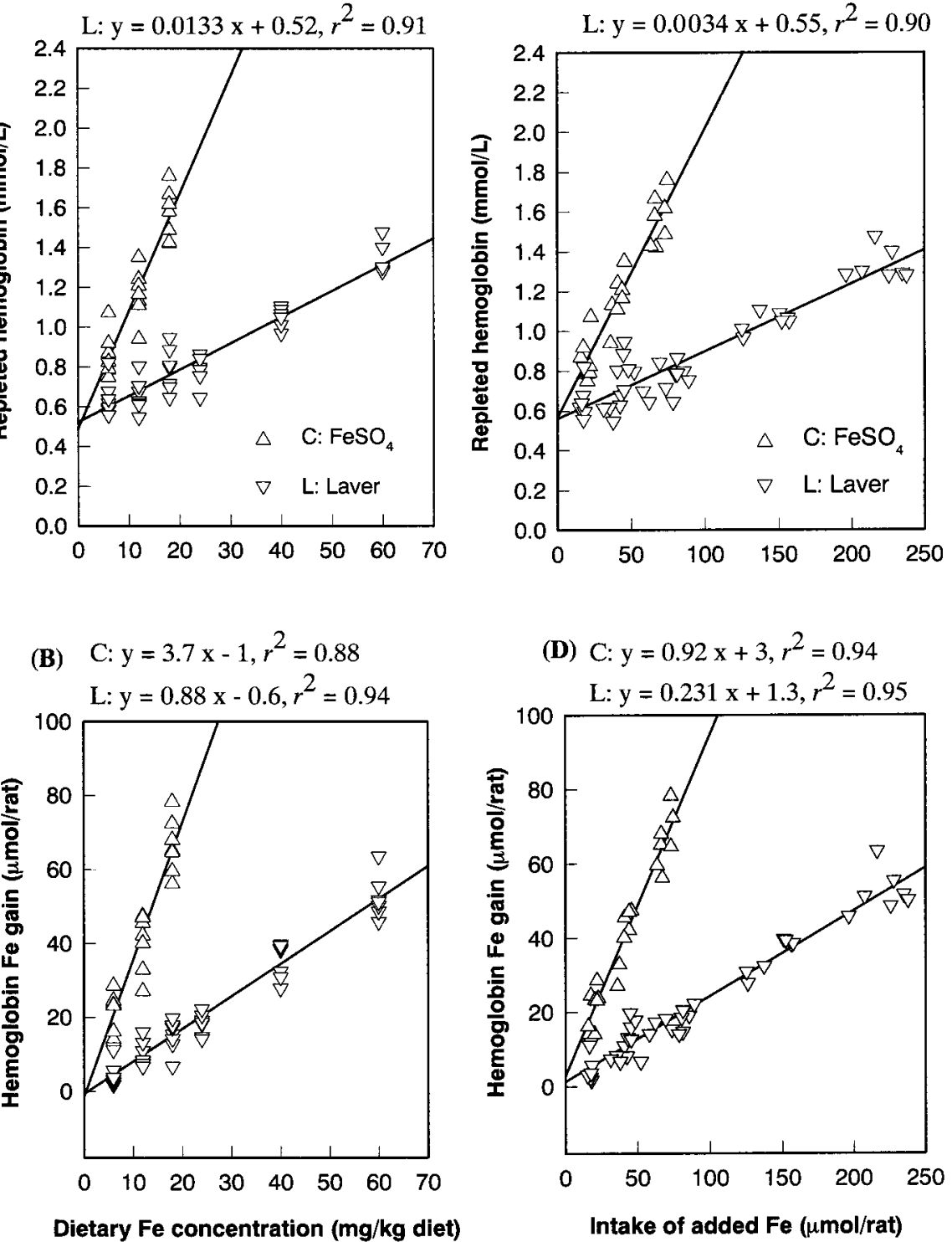

Dietary Fe concentration ( $\mathbf{m g} / \mathbf{k g}$ diet)

Figure 1. Regression analysis of hemoglobin responses on dietary iron from laver in a rat hemoglobin regeneration bioassay in comparison to ferrous sulfate standard diets. Data of individual rats were shown in each plot. Significance was set at $\mathrm{p}=0.0001$. Parts $A$ and $B$ are regenerated hemogl obin concentrations and hemoglobin Fe gain on dietary Fe concentration, respectively. Parts $C$ and $D$ are regenerated hemoglobin concentration and hemogl obin Fe gain on intake of added Fe, respectively.

thus calculated ranged from 24 to 26 . The best correlation was obtained from the function of hemoglobin $\mathrm{Fe}$ gain versus intake of added Fe (Figure 1D).

\section{DISCUSSION}

In calculating the average HRE and regression analysis for the standard diets, data from the standard group at $35 \mathrm{mg} \mathrm{Fe} / \mathrm{kg}$ were not included. This level of iron was above the sub-optimal iron requirement of the rat so as that response in body weight as well as in regenerated hemoglobin concentration tended to deviate from a linear relationship. This deviation was imposed by physiological homeostasis of iron metabolism and did not represent true availability of iron.

J ohnson and Evans (1978) observed that absorption of ferrous sulfate in rapidly growing, iron-depleted rats approached $100 \%$. In this study, HRE for the standard groups fed diets at suboptimal iron levels was near $100 \%$, indicating that HRE in iron-deficiency anemic rats was equivalent to iron absorption rate and truly reflected iron availability. Therefore, the low and consistent HRE for the laver groups was a result of limited iron availability at low or high iron concentrations.

Our data fit the slope-ratio model well for analysis of RBV (Amine and Hegsted, 1974). Regression analysis of the linear dose-response relationship was highly significant, indicating that iron level was the major determinant of the hemoglobin response in the regeneration period for both standard and laver diets. Projections of the regression lines in Figure 1 to the zero iron intercept (Y axis intercept) yielded a value similar to that of the depletion group. F or example, intercepts for regenerated hemoglobin concentrations ranged from 0.49 to $0.57 \mathrm{mmol} / \mathrm{L}$ and for hemogl obin F e gains ranged from -0.6 to $3 \mu \mathrm{mol} / \mathrm{rat}$, which were close to the mean of $0.57 \pm 0.15 \mathrm{mmol} / \mathrm{L}$ and $1 \pm 4 \mu \mathrm{mol} / \mathrm{rat}$ for the depletion group, respectively. Therefore, these hemogl obin responses were contributed solely by the added iron and can be taken as a quantitative indicator of the bioavailability of iron source. 
Several authors (Miller, 1977; Rotruck and Luhrsen, 1979) have suggested that dose-response correlation can be improved with each mathematical adjustment for individual animal differences. Between the two measures of dietary $\mathrm{Fe}$, iron intake consistently gave the better correlation (Figure 1 ) because variation in food intake among animals was corrected. Among the two measures of hemogl obin regeneration, hemoglobin Fe gain gave consistently better correlation than hemogl obin concentration for both di etary groups (Figure 1) because the former have taken into account the differences in weight gain, and thus in expansion of blood volumes during the regeneration period.

Both slope-ratio and HRE methods yiel ded consistent RBV for laver iron. Food with a RBV of $26 \%$ had iron availability lower than electrolytic iron, but similar to or higher than ferric orthophosphate or sodium iron pyrophosphate (Fritz et al., 1970; F orbes et al., 1989). However estimated, the amount of available iron from laver is comparable to those from many iron-fortified foods (Amine and Hegsted, 1974) when the high iron concentration (ranged from $0.28 \mathrm{mg}$ to $0.91 \mathrm{mg}$ Fe/g dry matter) had been considered. I ron in foods or diets comprises heme iron and non-heme iron pools (Hallberg, 1981). Laver can be used as a natural iron source in diets or as food ingredients to add to the non-heme iron pool.

\section{ABBREVIATIONS USED}

RBV, relative biological value; HRE, hemoglobin regeneration efficiency.

\section{LITERATURE CITED}

American Institute of Nutrition. Report of the American Institute of Nutrition ad hoc committee on standards for nutritional studies. J . Nutr. 1977, 107, 1340-1348.

Amine, E. K.; Hegsted, D. M. Biological assessment of available iron in food products. J . Agric. Food Chem. 1974, 22, 470475.

AOAC Official Methods. Bioavailability of iron, rat hemoglobin regeneration bioassay. In Official Methods of Analysis; Williams, S., Ed.; Association of Official Analytical Chemists: Arlington, VA, 1995; Chapter 45, pp 62-63.

Crosby, W. H.; Munn, S. I. Standard method for clinical hemogl obinometry. US Arm Force Med. J . 1954, 51, 693703.

FAO. Food Composition Table for Use in East Asia. FAO, Rome, I taly, 1972.

FAOMHO. Requirements of Vitamin A, Iron, Folate and Vitamin $B_{12}$; FAO, Rome, Italy, 1988.

Forbes, A. L.; Adams, C. E.; Arnaud, M. J .; Chichester, C. O.; Cook, J. D.; Harrison, B. N.; Hurrell, R. F.; Kahn, S. G.; Morris, E. R.; Tanner, J. T.; Whittaker, P. Comparison of in vitro, animal, and clinical determinations of iron bio- availability: I nternational Nutritional Anemia Consultative Group task force report on iron bioavailability. Am. J . Clin. Nutr. 1989, 49, 225-238.

Fritz, J . C.; Pla, G. W.; Harrison, B. N.; Clark, G. A. Collaborative study of the rat hemoglobin repletion test for bioavailability of iron. J . Assoc. Off. Anal. Chem. 1974, 57, 513517.

Hallberg, L. Bioavailability of dietary iron in man. Annu. Rev. Nutr. 1981, 1, 123-147.

J ohnson, P. E.; Evans, G. W. I ron absorption by rats from nonprescription dietary iron supplements. J . Agric. Food Chem. 1978, 26, 844-847.

Mahoney, A. W.; Hendricks, D. G. Efficiency of hemoglobin regeneration as a method of assessing iron bioavailability in food products. In N utritional Bioavailability of I ron; Kies, C., Ed.; ACS Symposium Series 203, American Chemical Society: Washington, DC, 1982; pp 1-10.

Miller, J . Study of experimental conditions for most reliable estimates of relative biological value of iron in bread. J. Agric. Food Chem. 1977, 25, 154-158.

Miller, J. Assessment of dietary iron availability by rat $\mathrm{Hb}$ repletion assay. Nutr. Rep. Int. 1982, 26, 993-1005.

Monsen, E. R.; Hallberg, L.; Layrisse, M.; Hegsted, D. M.; Cook, J . D.; Mertz, W.; Finch, C. A. Estimation of available dietary iron. Am. J . Clin. Nutr. 1978, 31, 134-141.

National Science Council. Guidelines for Use and Care of Laboratory Animals; National Science Council: Taipei, Taiwan, 1993.

Noda, H. Health benefits and nutritional properties of nori. J. Appl. Phycol. 1993, 5, 255-258.

Noda, H.; Amano, H.; Arashima, K.; Nishizawa, K. Antitumor activity of marine algae. In Thirteenth International Seaweed Symposi um. Devel opments in Hydrobiology 58; Lindstrom, S. C., Gabrielson, P. W., Eds.; Kluwer Academic Publishers: Dordrecht, 1990; pp 577-584.

Okai, Y.; Higashi-Okai, K.; Yano, Y.; Otani, S. Identification of antimutagenic substances in an extract of edi ble red alga, Porphyra tenera (Asakusa-nori). Cancer Lett. 1996, 100, 235-240.

Rotruck, J . T.; Luhrsen, K. R. A comparative study in rats of iron bioavailability from cooked beef and soybean protein. J . Agric. Food Chem. 1979, 27, 27-33.

United Nation ACC/SCN. Second Report on the World Nutrition Situation. ACC/SCN, Geneva, Switzerland, 1992.

Watanabe, F.; Takenaka, S.; Katsura, H.; Zakir Hussain Masumder, S. A. M.; Abe, K.; Tamura, Y.; Nakano, Y. Dried green and purple lavers (nori) contain substantial amounts of biologically active vitamin $B_{12}$ but less of dietary iodine relative to other edible seaweeds. J . Agric. Food Chem. 1999, 47, 2341-2343.

Yamada, S.; Shibata, Y.; Takayama, M.; Narita, Y.; Sugawara, K.; Fukuda, M. Content and characteristics of vitamin $B_{12}$ in some seaweeds. J. Nutr. Sci. Vitaminol. 1996, 42, 497505.

Received for review J uly 12, 1999. Revised manuscript received J anuary 20, 2000. Accepted February 7, 2000.

J F 990759Y 